\title{
Stem cells in homeostasis and cancer of the gut
}

\author{
Maartje van der Heijden and Louis Vermeulen ${ }^{*}$
}

\begin{abstract}
The intestinal epithelial lining is one of the most rapidly renewing cell populations in the body. As a result, the gut has been an attractive model to resolve key mechanisms in epithelial homeostasis. In particular the role of intestinal stem cells (ISCS) in the renewal process has been intensely studied. Interestingly, as opposed to the traditional stem cell theory, the ISC is not a static population but displays significant plasticity and in situations of tissue regeneration more differentiated cells can revert back to a stem cell state upon exposure to extracellular signals. Importantly, normal intestinal homeostasis provides important insight into mechanisms that drive colorectal cancer (CRC) development and growth. Specifically, the dynamics of cancer stem cells bear important resemblance to ISC functionality. In this review we present an overview of the current knowledge on ISCs in homeostasis and their role in malignant transformation. Also, we discuss the existence of stem cells in intestinal adenomas and CRC and how these cells contribute to (pre-)malignant growth. Furthermore, we will focus on new paradigms in the field of dynamical cellular hierarchies in CRC and the intimate relationship between tumor cells and their niche.
\end{abstract}

Keywords: Intestinal stem cells, Cell plasticity, Cancer stem cells, Tumor (micro-)environment, Colorectal cancer

\section{Background}

The intestinal tract is a widely studied organ with a multitude of functions. Besides its primary purpose to absorb nutrients and remove feces, it is also a major player in the regulation of metabolic and immune processes in the human body. These different functions reflect the complexity of this organ and highlight the enormous interplay that exists between the extensive cellular and non-cellular parts that make up the intestinal tract including: epithelial cells, immune cells, stromal cells, hormones and neurotransmitters, nutrients, the microbiome and many more. Hence, it comes as no surprise that many diseases are associated with malfunctioning of the intestine, such as infectious and autoimmune disorders. Colorectal cancer (CRC) is another common disease that arises from the colonic epithelial layer.

CRC is a significant cause of cancer related death and worldwide the incidence is still increasing [1]. Early stage disease is often still curable but the availability of effective curative therapies for disseminated CRC is very

\footnotetext{
* Correspondence: I.vermeulen@amc.uva.nl

Amsterdam UMC, University of Amsterdam, Laboratory for Experimental Oncology and Radiobiology, Center for Experimental and Molecular Medicine, Cancer Center Amsterdam and Amsterdam Gastroenterology and Metabolism, Meibergdreef 9, 1105 Amsterdam, AZ, Netherlands
}

limited. Throughout the years much emphasis has been put on genetic causes of cancer, in particular the oncogenic driver and tumor-suppressor gene mutations [2]. For CRC, already decades ago, genomic aberrations that are associated with the progression of polyps and adenomas to CRC were identified [3]. To date CRC is the prime example of step-wise carcinogenesis. However, the biology of CRC contains so many more facets than the genetic aberrancies present within tumor cells. In particular the (micro-)environment is of great relevance in shaping the clinical presentation of the disease, and key to understanding process including metastasis formation and therapy failure [4-6]. As for other cancer types, another phenomenon that is hugely complicating therapy responses is the observed inter- and intratumor heterogeneity $[7,8]$. First of all, intertumor heterogeneity referring to the differences between patients presenting with $\mathrm{CRC}$, is extensive, and relates to clinical as well as genetic properties. Transcriptomic profiling of CRCs led to the identification of four main CRC subtypes $[9,10]$. These subtypes differ in genetic aberrations, composition of the immune infiltrate and other features of the stromal compartment, as well as the clinical outcomes of the disease. Underneath these molecular subgroups lies

(c) The Author(s). 2019 Open Access This article is distributed under the terms of the Creative Commons Attribution 4.0 International License (http://creativecommons.org/licenses/by/4.0/), which permits unrestricted use, distribution, and 
another important layer of complexity, namely the cellular intratumor heterogeneity. It has been recognized that CRCs contain extensive genetic variability reflecting the ongoing accumulation of mutations and competition for space and nutrients. Simultaneously, individual CRCs contain cells with different differentiation grades, also in genetically homogenous clones. It is thought that these cells reflect different stages of differentiation that mirror the differentiation patterns found in the normal intestine. It has also been postulated that these various degrees of differentiation are accompanied by functional differences, with stem cell-like cells: cancer stem cells (CSCs) driving tumor growth and progression. This hierarchical tumor model has also served as an attractive explanation for therapy failure as it has been described that CSCs are more resistant to conventional therapies and therefore are likely seeds of tumor relapse.

Stem cell biology plays an equally important role in another aspect of CRC biology. It is believed that intestinal stem cells (ISCs) are the cell of origin of the large majority of CRCs [11]. Therefore, understanding the properties of ISCs in detail is likely to contribute to a better understanding of CRC development and progression. In the past decade, major advances have been made to reveal the ISC identity (Table1). Crucially, it appears that the ISC state and consequently the ISC identity is highly dynamic. Accordingly, pinpointing one demarcated group of cells as the ISCs has been proven difficult. Similarly, the plasticity of ISCs is also reflected in CSCs as recent work demonstrates, and prone to greatly hamper the efficacy of CSC-specific targeted therapies. In this review, we provide an overview of ISCs in homeostasis and tumor initiation, and crucially their interplay with the environment which directly impacts on cellular differentiation grades. In analogy with this, we will review the current knowledge on colorectal CSC biology. As opposed to the initially rigid CSC theory, that viewed CSCs as rare and intrinsically distinct entities, it becomes increasingly evident that the CSC state

Table 1 Different characteristics of intestinal (cancer) stem cell behavior

ISC or CSC phenotype: this indicates the identification of stem cells based on the expression of certain markers or pathway-activities, which are associated with stem cell features, such as self-renewal and multi-potency.

ISC or CSC activity: this indicates whether a specific intestinal or CRC cell population shows active stem cell behavior as found by clonal lineage tracing experiments.

ISC or CSC potential: this indicates an inactive stem cell state in homeostasis but the ability of cells to reversibly undergo

dedifferentiation in specific circumstances. For example, for differentiated cells in an inflammatory environment and CRC cells that receive specific stromal signals, i.e. Osteopontin.

ISC or CSC functionality: this indicates the underlying stem cell dynamics of all active ISCs or CSCs present in a specific situation, e.g. during ISC homeostasis or CRC growth. is subjected to cellular plasticity and importantly, might be much more common than previously expected. To conclude, we will highlight the current insights on how stem cell features potentially impede the effects of anti-cancer therapy in CRC.

\section{Intestinal stem cells \\ Intestinal stem cells in homeostasis}

The intestinal lining consists of a monolayer of epithelial cells covering the stromal compartment of the gut, and is characterized by a tight regulation and an immense turn-over capacity. All intestinal epithelium cells are replaced every $3-4$ days in mice and this renewal rate is speculated to be approximately every week in the human colon [12]. This rapid renewal is likely to be important for limiting the amount of damaged epithelial cells due to the many bacteria and (toxic) chemicals that pass by inside the lumen and which are continuously in direct contact with these cells. The small intestinal epithelial layer contains a heterogeneous pool of cells, starting from the bottom of the crypts towards the top of the villi (Fig. 1a). Globally, along the crypt-villus axis, the ISCs reside in the bottom region of the crypt, whereas progenitors and differentiated cells are found more towards the top of crypts and villi, respectively [13]. The most abundant differentiated cell is the absorptive enterocyte. Furthermore, there are various secretory cells, only consisting of a few percent of all cells, which comprises the mucus producing Goblet cells, Paneth cells, Enteroendocrine cells, and the very rare Tuft and Microfold (M) cells [13]. All these cells contribute to specific tasks of the intestine.

The incredible epithelial turnover is sustained by ISCs that reside in the bottom of the crypts. With the development of lineage tracing technology our knowledge of ISCs underwent a transformation. In a seminal study from the laboratory of Hans Clevers leucine-rich-repeat-containing G-protein-coupled receptor 5 expressing $\left(\mathrm{Lgr}^{+}\right)$cells were demonstrated to function as bona fide stem cells [14]. These Lgr $5^{+}$cells, are slender cells squeezed in between the Paneth cells and were already previously described as crypt base columnar cells (CBCs) by Cheng and Leblond $[15,16]$. Already in 1974 these CBCs were considered as rare, long-lived and slow-cycling cells $[15,16]$. In fact, $\mathrm{CBCs}$ are actively cycling and continuously contributing to fuel the whole crypt-villus axis with newly generated epithelial cells. Subsequently, many markers have been identified in lineage tracing experiments of which most directly overlap with the $\operatorname{Lgr} 5^{+}$population, for example: B lymphoma Mo-MLV insertion region 1 homo$\log$ (Bmi1) [17], HOP homeobox (Hopx) [18], SPARC related modular calcium binding 2 (Smoc2) [19], mouse telomerase reverse transcriptase (mTert) [20], SRY-box 9 (Sox9) [21], leucine rich repeats and immunoglobulin like 


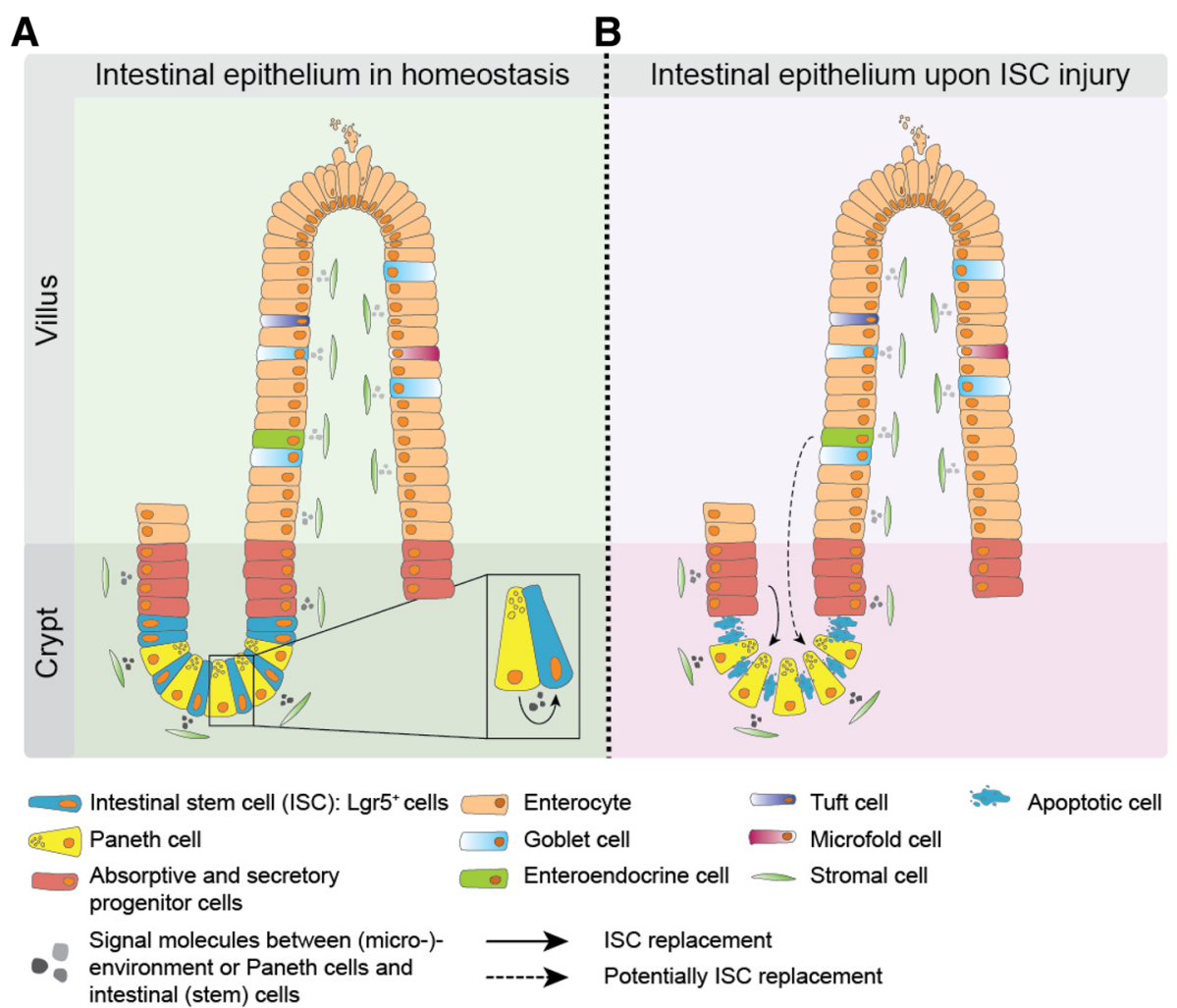

Fig. 1 The intestinal epithelium. (a) The intestinal lining consists of an epithelial monolayer covering invaginations (crypts) and finger like protrusions (villi, only in the small intestine). Intestinal stem cells (ISC) reside in the bottom of the crypts, absorptive and secretory progenitor cells directly above the ISC zone, and more differentiated cells towards the top of crypts and on the villi. Intestinal progenitor and differentiated cells move upwards due to the massive tissue renewal fueled by the ISCS. This is a continuous process and it only takes several days before differentiated cells undergo apoptosis and are shed into the gut lumen. (b) The ISC compartment is sensitive to cytotoxic injury, such as irradiation. Consequently, upon DNA damage ISCs undergo apoptosis. The progenitor cells located higher up in the crypt replace the loss of ISCS and due to the new topological position regain niche signals, which then install ISC activity. Therefore, the ISC compartment is a dynamic population and progenitor- and potentially fully differentiated cells, show an enormous cellular plasticity upon ISC loss

domains 1 (Lrig1) [22], and prominin 1 (Prom1) [23, 24]. Virtually all these markers are located primarily in the CBC position intermingled with Paneth cells and in position +4 right above the bottom of the crypt. Paneth cells provide a niche for the ISCs by critically excreting factors that contribute to the ISC state, in particular Wnt ligands [25]. In the bottom of murine crypts, $\sim 14$ highly proliferative and equipotent $\mathrm{Lgr}^{+}$cells are found that divide every day and replace each other in a stochastic fashion, in a process that is referred to as neutral drift [26-28]. In time this leads to niche succession and ultimately the generation of a clonally related population within the crypt [26-28]. Intriguingly, the cellular position is closely linked to the function of intestinal cells as cells from the $\mathrm{Lgr}^{+}$population do not have equipotent chance in gaining niche fixation [29]. Niche fixation chances are in favor of the bottom stem cells as they are less likely to be replaced, simply due to their topological position close to the niche [29]. By using a marker-free lineage tracing approach in combination with a quantitative stochastic model we demonstrated that only five to seven
ISCs are predominantly participating in constantly achieving niche fixation [30]. Interestingly, these ISCs do not act alone but are involved in an intimate relationship with their (micro-)environment as we will describe hereafter.

\section{Intestinal cell plasticity}

The intestine demonstrates impressive regeneration potential in case of intestinal injury, as depletion of all Lgr $^{+}$ISCs does not result in crypt loss and complete regeneration of the affected crypts occurs [31, 32]. Fast-cycling $\operatorname{Lgr}^{+}$cells are vulnerable to DNA damage caused by for example radiation or cytostatic agents because of their highly proliferative state. In response to loss of $\mathrm{Lgr}^{+}$cells due to these types of injury, two cell types are believed to be responsible for replenishing the ISC pool and sustaining epithelial homeostasis; 1) slow-cycling, quiescent cells at the +4 position (also called ' +4 ' cells) within crypts and 2) absorptive and secretory progenitors (Fig. 1b) [33-36]. However, it is still debated whether the ' +4 ' cells are truly distinct from 
the $\operatorname{Lgr} 5^{+}$cells as these two populations show evident overlap in marker expression, e.g. Bmi1, mTert, Lrig1, Hopx, Atoh1 and Mex3A [35, 37, 38]. Additionally, also the Paneth precursor label-retaining cell (LRC) population on the '+4' position can acquire stem cell properties upon tissue injury [39]. Recently it was found that despite differential lineage fates, a subpopulation of $\operatorname{Lgr} 5^{+}$ cells and LRCs show overlapping transcriptomic signatures, indicating not a clear separation between ' $1-3$ ' and ' +4 ' positioned crypt cells [37]. In conclusion, $\mathrm{CBC}$ cells display functional marker expression differences based on their location within the crypt bottom but seem uniformly capable of multipotent behavior, albeit in different circumstances. Two factors seem important for this bidirectional conversion: 1) the intrinsic ability to switch cell fate, e.g. by chromatin remodeling [40], and 2) receiving niche signals for reversibly gaining ISC phenotype and functionality [25]. Crucially, retrieval of specific niche factors, as provided by Paneth cells, due to the newly obtained topological position following CBC loss is necessary to re-gain ISC activity [25]. Also, interestingly, it was found that upon transitioning from ISC to differentiated cell state major changes take place on the chromatin accessibility sites of many cell-type specific genes [40]. When required, these sites can completely revert from a closed to an open state and thereby switching between different cellular functionalities. It is plausible that dynamic chromatin remodeling is one of the key factors underlying the cell-fate switch [40]. In contrast, the epigenetic status as witnessed by genome-wide DNA methylation patterns remains relatively stable upon (de-)differentiation [41, 42]. However, it remains yet unknown whether there is a point-of-no-return maturation state for undergoing de-differentiation (Fig. 1b). Recent work has indicated that even terminally differentiated Paneth cells and late-stage entero-endocrine cells, still have the capacity to switch back to an ISC state, indicating that conceivably any intestinal epithelial cell is equipped with this potential [43-45].

\section{Signals regulating intestinal stem cells}

As in other organ systems, ISCs rely heavily on signals from the stem cell environment, i.e. the niche [46]. The Paneth cells constitute a key part of the ISC niche and are a source of factors like epithelial growth factor (EGF), transforming growth factor- $\alpha$ (TGF- $\alpha$ ), Wnt3 and the Notch ligand Delta-like 4 (Dll4) [25]. Wnt pathway activation is arguably the most important pathway for installing the ISC phenotype and seems to overrule other pathways to do so [25, 47]. The mesenchymal cell layer surrounding $\mathrm{CBC}$ cells is also an important source of Wnt signals [48-50]. In addition, Notch, EGFR/MAPK and ErbB are other signaling routes, that are important for ISC maintenance [25, 51]. Bone morphogenetic protein (BMP) signaling, on the other hand, inhibits stem cell expansion and is actively repressed by the antagonist Noggin in the niche [52, 53]. BMP and Ephrin-B signaling are indeed increasingly expressed from the crypt bottom towards the villus tips in a transient manner thereby promoting differentiation of epithelial cells when these cells move upwards on the crypt-villus axis [54]. Conversely, inactivation of the BMP pathway results in excessive ISC niche expansion [55]. Similarly, deprivation from Wnt signals due to the cellular position directs cells towards differential lineages [56]. The heterogeneous progenitor compartment is regulated by an interplay of differently expressed pathways [13]. Stochastic processes as well as signals received from stroma or neighboring cells underlie the complex coordination of the formation of various intestinal lineages (lateral inhibition chromatin remodeling) [42]. Instantly after cells leave the Wnt-rich environment signaling routes such as Notch, BMP and EGFR/MAPK come into play. Notch activation in progenitor cells is mediated by paracrine signaling through secretion of Delta-like 1 (Dll1) and Dll4 ligands and leads to an absorptive lineage formation [57]. In agreement, chemical inactivation of Notch signals drives progenitor cells towards the secretory fate [58]. Conversely, it is hypothesized that stochastic Notch repression in progenitor cells induces also Atoh1 (also known as Math1) expression, which is essential for commitment towards the secretory lineage [59]. Furthermore, the difference between active and quiescent ' +4 ' Lgr $^{+}$cells potentially results from differences in Wnt and EGFR/MAPK activity. The slow-cycling '+ 4' LRCs are Wnt ${ }^{\text {high }}$ but have reduced EGFR expression, which then limits proliferation [60]. Furthermore, the BMP gradient along the crypt-villus axis directly results in different hormone excretion profiles of entero-endocrine cells [61]. All of these signaling pathways involved in the murine intestinal epithelium serve as a great model for human intestinal biology. However, the colonic stem cell dynamics in mice are much less defined and the murine colonic epithelium is much less susceptible to malignant transformation in many models. This is important because human CRC mostly arises in the colonic tract and these pathways might elicit different effects on human colonic epithelial cells. This should be anticipated when translating knowledge obtained in the murine small intestine, to the human situation.

\section{Colonic stem cells}

The murine colonic epithelium shows a similar cryptstructured pattern as compared to the small intestine but lacks villi. The colonic crypt is also populated with stem cells in the bottom that produce specialized cells that cover the crypt wall. However, the cellular composition 
differs from the small intestine as Paneth cells, the ' +4 ' population and $\mathrm{Bmil}^{+}$cells are absent. However, other crypt bottom cells (e.g. $\mathrm{cKIT}^{+}$and Reg4 ${ }^{+}$cells) intermingling with the $\operatorname{Lgr} 5^{+}$population are present and express growth factors reminiscent to Paneth cells in the small intestine [62, 63]. Also, Wnt signals derived from the mesenchymal cell population surrounding the colonic crypts are critical for stem cell renewal and tissue maintenance [64]. Colonic stem cells have also been identified as Lgr5 $5^{+}$ and EphrB2 ${ }^{\text {high }}[14,65,66]$. Additionally, cell cycle differences have been found among the colonic stem cell population, of which high Notch and Lrig1 expression mark the slow cycling population [22, 67].

Clearly, applying transgenic lineage tracing techniques in humans is not feasible. However, different lineage tracing techniques based on neutral somatic mutations have been successfully applied to study stem cell dynamics in the adult colon $[26,68]$. These studies show an estimated number of functional colonic stem cells that each contribute in a stochastic fashion to spawning new clonal lineages, ranging between five to six or five to ten active stem cells $[26,68]$. Importantly, human stem cells have a significant slower niche fixation rate compared to their murine intestinal counterparts. On average one colonic stem cell is predicted to be replaced every year within a crypt in contrast to the murine colon where the replacement rate is much higher, namely every three days $[30,68]$. Hence, while general concepts of stem cells dynamics are conserved between mice and humans, the rates can be highly different.

\section{Tumor initiation in the intestine Cell-of-origin}

Generally it is assumed that the 'cell-of-origin' for most cancers is a tissue-specific stem cell [69]. Evidently, their long-term clonogenic potential required for tissue sustenance makes stem cells ideal candidates to accumulate DNA alterations and initiate cancer. Also, in case of the intestinal epithelium, the stem cell compartment is life-long maintained, in contrast to the differentiated cells that are shed into the lumen within a week. Evidently, this limits their potential to clonally expand. However, morphologic analysis of human adenomas showed evidence that in some cases, the intestinal cells higher up in the crypts are responsible for adenoma initiation and not the stem cells in the crypt base. This has been posted as the 'top-down' model for adenoma initiation [70]. The large majority of the CRCs harbor a mutation in the adenomatous polyposis coli $(A P C)$ gene, and this gene is identified as one of the initial oncogenic events in CRC [3]. The APC protein is a key member of the $\beta$-catenin degradation complex [71]. Mutations within APC result in ineffective targeting of $\beta$-catenin for degradation and causes a constitutively active Wnt pathway which results in an expanding ISC compartment followed by adenoma formation [72]. In genetic mouse models adenomas only appeared when this mutation was specifically introduced in ISCs, for example in in $\mathrm{Lgr5}^{+}, \mathrm{Bmil}^{+}$or Proml $^{+}$cells $[11,17,23]$, while Apc mutations targeted to the differentiated cells only resulted in indolent cystic structures [11] (Fig. 2a). In contrast, full adenomatous outgrowth was also observed upon combined activation of constitutive active Wnt and the nuclear factor- $\mathrm{kB}$ (Nf- $\mathrm{\kappa B})$ pathway in the differentiated compartment (Fig. 2b) [73]. As we previously showed, one of the key mediators that allows for ISC transformation is the anti-apoptotic protein BCL-2 which is both highly expressed in Lgr $5^{+} \mathrm{CBCs}$ and a target gene of the Nf- $\kappa B$ pathway [74]. Moreover, given the ability of intestinal epithelial cells to undergo extensive plasticity during tissue damage and regeneration, it seems likely that inflammatory signals from the environment install differentiated cells with a similar oncogenic potential as the ISC cells. Another example is the post-mitotically differentiated Tuft cell population which in homeostasis do not contribute to tissue renewal, but in case of intestinal injury displays ISC activity and also intestinal polyp forming capacity only in a colitis setting [75, 76]. We speculate that functional cellular transitions occur under influence of extrinsic factors and a major role seems to be reserved for the cellular (micro-)environment. Another observation supporting this hypothesis, is the increased risk for CRC development in patients with chronic colitis $[77,78]$ and the reduced risk of colorectal adenoma development upon anti-inflammatory drug treatment, such as celecoxib and aspirin [79, 80]. Reduction of an inflammatory phenotype via COX-2 inhibition led to a decrease in polyp burden [81] and reduces the risk for the development of colorectal cancer [82]. Therefore, (micro-)environmental factors that enhance inflammatory pathways, e.g. Nf-kB pathway activation, seem to underlie the risk of CRC development. Potentially by expanding the pool of cells amendable for malignant transformation.

\section{Niche fixation of mutated cells}

Mutations that are involved in the malignant transformation of intestinal epithelial cells have been well-defined [3]. For CRC, in many cases this involves a mutation in the tumor-suppressor genes APC and TP53, and the oncogene KRAS [3]. Recently, the quantitative dynamics of these mutations and the impact on the clonal behavior of ISCs have been investigated by us and others [83, 84]. As mentioned above, the fast-cycling CBCs are most susceptible for initiating clonal lineages that carry a specific mutation. In homeostasis, ongoing stochastic competition takes place among the 5-7 functional ISCs [27, 28]. These dynamics follow the 'neutral drift' model, indicating the random replacement behavior of ISCs in the 


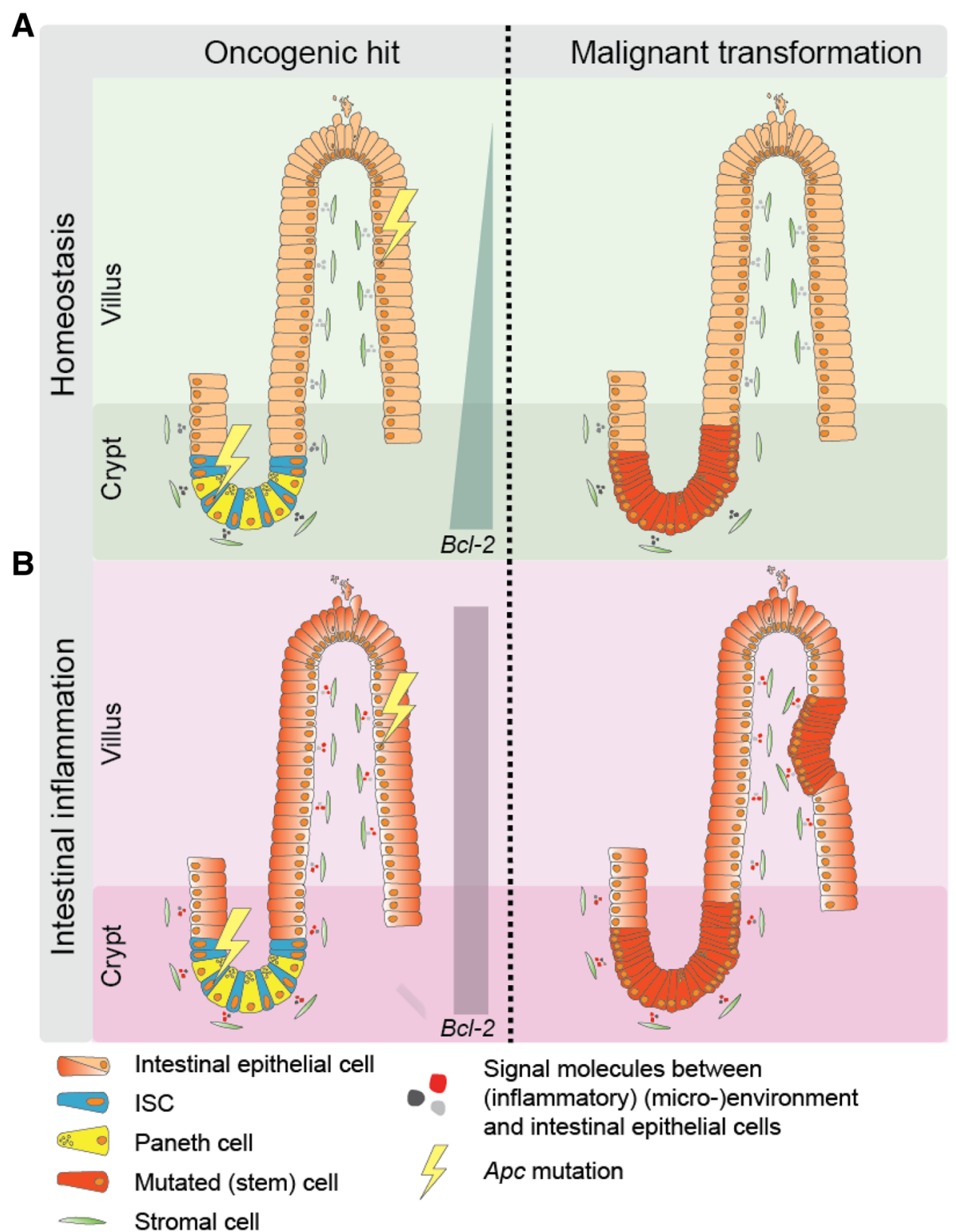

Fig. 2 Intestinal cell plasticity dynamics in malignant transformation. (a) ISCs have the ability to effectively initiate adenoma formation when these cells acquire Apc mutations. On the other hand, differentiated intestinal epithelial cells do rarely undergo malignant transformation upon obtaining an oncogenic hit. (b) However, in an inflammatory environment differentiated cells acquire similar transformation potential. Different factors underlie the differences in transformation capacity of ISCs versus differentiated cells. First of all, the topological position of differentiated cells prevents them in homeostasis from generating long-lived clonal lineages. Secondly, the ISC niche endows ISCS with the potential to endure the stressors that result from acquiring an oncogenic mutation [74]. Similarly, in a colitis environment the differentiated cell compartment is also installed with anti-apoptotic capacities through activation of the nuclear factor-kB (Nf-kB) pathway [73]. The anti-apoptotic protein BLC-2 is one of the identified mediators that facilitates this oncogenic transformation. Indeed, inhibition of BCL-2, either genetically or pharmacologically, reduced adenoma burden in mice [74]

crypt bottom. However, when an ISC acquires an oncogenic mutation, for example in Apc or Kras, a bias ensues in favor of the mutant cells (biased-drift) [83, 84]. For example, the probability of a $\mathrm{Kras}^{\mathrm{G} 12 \mathrm{D}}$ mutated cell to replace its neighbor ISCs and finally become clonal within a crypt is respectively $60-70 \%$ in comparison with $12,5-$ $20 \%$ for non-mutated ISCs [83, 84]. Importantly, although the mutated ISC gains a higher probability of niche fixation, these cells are still subjected to undergo replacement by normal ISCs. Interestingly, Trp53 mutations only present with a superior niche fixation rate in case of colitis, which again underscores the importance of extrinsic factors in malignant transformation of intestinal cells [83]. 
The morphological tissue architecture of the intestine prevents rapid spreading of mutated cells as each of these crypts is a dynamic cellular niche on its own without any exchange of cells in between crypts. However, the number of crypts is not stable due to two processes called fission and fusion, meaning respectively bifurcating and colliding crypts [85]. These counteracting processes compensate for each other and are both in man and mice an infrequent event, unless tissue damage occurs [85-89]. Interestingly, a much higher fission rate is observed in Kras mutated crypts [84]. This is also illustrated by the notion that multiple KRAS mutated neighboring crypts can be found surrounding a CRC, suggesting that within a field of KRAS mutant crypts one crypt has undergone further transformation [90]. Therefore, crypt fission seems to be an important mechanism for malignant transformation and progression in the intestine, involving a process referred to as field cancerization. In a clinical setting, it would be relevant to therapeutically prevent the process of field cancerization, as it would significantly decrease the risk of CRC development by simply keeping the numbers of mutated crypts as low as possible.

\section{Clonal expansion in the intestine \\ Adenoma formation and growth}

Once an adenoma is formed upon expansion of mutated crypts and at least $1 \mathrm{~cm}$ in size, there is a $\sim 25 \%$ risk of this newly formed adenoma to undergo malignant transformation towards an invasive carcinoma in the following two decades [91]. Mechanisms that underlie this progression are nearly impossible to capture in humans. Unfortunately, there is also a lack of tumor mouse models that mimic invasive growth. Nevertheless, several groups successfully investigated the stem cell compartment in these benign tumors in both mice and man [30, 92, 93]. First of all, the morphology of adenomas containing glandular structures closely resembles the healthy crypt-structured intestine and these also contain a range of different cell types [92]. Upon adenoma initiation in $\mathrm{Lgr}^{+}$cells, lineage tracing was performed by so-called 're-tracing' of the $\operatorname{Lgr} 5^{+}$population in established adenomas. This showed that also in adenomas the Lgr $5^{+}$cell population in the bottom of glands, display a similar repopulating potential as their normal counterparts within the glandular structures [92]. Similarly, clonal tracing from the rare doublecortin-like kinase 1 $(D c l k 1)$ positive cell population in the $A p c^{\text {min }}$ mouse model showed the clonogenic properties of these cells and ablation of the $D c l k 1^{+}$cell population results in adenoma volume reduction [76]. We contributed to further quantitative insight into the stem cell dynamics within adenomatous tissue using a marker independent clonal tracing strategy [30]. This method revealed that in adenomatous crypts $\sim 9$ functional stem cells are present per hundreds of cells within each gland. This is in contrast with the percentage of $\operatorname{Lgr} 5^{+}$cells that is found within the adenomas, approximately $\sim 20 \%$ of the total population ( 400 cells per gland). Therefore, it seems unlikely that each $\operatorname{Lgr} 5^{+}$cell exhibits similar stem cell activity [92]. Similarly, in case of human adenomas, multi-lineage differentiation was demonstrated within glandular structures, which suggests the existence of multi-potent stem cells [93]. Here, clonal tracing was performed by exploiting the random occurrence of stable non-oncogenic mutations in the mitochondrial genome that can be visualized by immunohistochemistry within individual adenomatous cells [93]. Methylation patterns of different clonal patches were very heterogeneous which indicates that already at early-stage tumorigenesis intra-adenoma (epigenetic) clonal diversity arises [93]. However, the underlying dynamics and effects on clonal behavior during malignant transformation have remained largely unresolved. Furthermore, gland fusion events are limited in adenomas and gland fission is assumed to be an important mechanism by which adenomas increase in size [94, 95]. Hypothetically, targeting crypt or adenoma gland fission events would be an attractive method to prevent the process of field cancerization or halt adenoma growth. However, further mechanistic insights would be necessary in order to develop these therapies.

\section{Intestinal cancer stem cells Intestinal stem cell plasticity and (micro-)environmental influences}

In analogy with intestinal epithelial turn-over, for many years it is believed that CRC growth and progression are fueled by a dedicated cancer cell population that possesses self-renewal and multi-potency potential, and these cells are referred to as cancer stem cells (CSCs) $[96,97]$. The presence of a cellular hierarchy explains the cellular heterogeneity, with respect to the differentiation grade, that is found within CRC $[6,98]$. This paradigm has been around for many decades and besides therapy failure may also explain phenomena such as tumor dormancy and metastasis. The normal intestinal epithelium displays great regeneration capacity upon injury due to the potential of epithelial cells to easily switch between differentiation states [31-35, 39]. In addition to specialized epithelial cells as Paneth and cKIT ${ }^{+}$ cells, it is well established that also the stromal compartment constitutes for crucial signals that are needed to equip cells with ISC functionality [49, 64]. Moreover, an inflammatory environment is another facilitating component that installs ISC functionality and thereby enhances the malignant transformation capacity of differentiated cells [73, 74]. Similarly, in human CRC, different signals 
directly derived from the tumor (micro-)environment have been found to induct a CSC phenotype and CSC functionality $[5,6,99]$. We would argue that plasticity of CRC cells is likely to be more pronounced as compared to normal intestinal epithelial cells although of course this is difficult to directly compare. This plasticity is exemplified in a mouse model that mimics human CRC growth and also a human CRC xenograft model $[4,100]$. Here, therapeutic ablation of the tumor-specific $\mathrm{Lgr} 5^{+}$cells in xenografts initially leads to impaired tumor growth $[4,100]$. However, shortly after discontinuation of $\mathrm{Lgr}^{+}$cell depletion therapy, tumor growth resumes at similar growth rates as untreated control tumors $[4,100]$. Specifically, Wnt-activating factors that are secreted by the stromal myofibroblast cell compartment include factors like hepatocyte growth factor (HGF) and Osteopontin, have demonstrated to elicit the CSC phenotype or activity $[5,6]$. In addition, TGF $\beta$ has similar effects but also elicits a migratory and pro-metastatic phenotype in cancer cells, either directly or via the cancer associated stromal cells [101103]. Importantly, dedifferentiation of non-CSCs to CSCs is predicted to greatly hamper effective responses to specific CSC targeted therapies [96]. Another complicating factor is the activating effect on tumor-associated stromal cells upon cytotoxic treatment. These cells show an increased secretion of specific chemokines and cytokines, e.g. interleukin-17A, that is able to sustain the CSC compartment [104]. Altogether, these studies suggest that specifically targeting the CSCs within CRC will likely not be sufficient. The CSC state is not a fixed entity due to intrinsic features, but rather highly dynamic and driven by environmental cues. In parallel, blocking of the (micro-)environmental signals that are derived from the tumor niche seems crucial in order to avoid replenishing of the CSC pool.

\section{Identification of the intestinal cancer stem cell}

This dynamic nature of CSCs complicates identification of the CSC pool in established CRC. Similarly for the normal intestine, previously distinct ISC states have been summarized in a comprehensive manner by four terms: the ISC phenotype, activity, potential and functionality (for description of these terms see Table 1, 38). Analogously, there is evidence that the highly dynamic nature of the intestinal epithelial cell compartment is mirrored in CRC and therefore identifying one defined CSC population that is unchangeably present in all circumstances has proven to be complex [6]. Initial efforts to identify the CSC population, mostly based on identification of the CSC phenotype and activity, started over a decade ago and has provided tremendous insights into cancer biology [97]. CSCs were identified based on differences in cell-surface marker expression and this essentially reflected the CSC phenotype and activity. This method originated from the field of hematological malignancies [105]. In these diseases it was shown that a subpopulation of leukemic cells that express cell-surface markers associated with immature cell types, was able to transmit leukemia upon injection into immune-compromised mice [106]. Hence, it was suggested that this method was also useful for distinguishing between the CSC and non-clonogenic differentiated/progenitor cell population in solid malignancies [97, 107, 108]. For long, the gold standard assay to test CSC activity in solid cancers was to study the tumor initiating capacity of cancer cells upon single cell sorting for these markers and then determining tumor outgrowth following subcutaneous or orthotopic injection of these cells in mice. In case of $\mathrm{CRC}$, multiple markers have been identified that were designated to reveal the CSC identity: $\mathrm{CD} 133^{+}$, EpCAMhigh $/ \mathrm{CD} 44^{+} / \mathrm{CD} 166^{+}, \mathrm{ALDH}^{+}, \mathrm{EphB2} 2^{\text {high }}$, and $\mathrm{Lgr}^{+}{ }^{+}[65$, 109-115]. Furthermore, additional markers have been described that are associated with specific CSC subsets characterized by distinct features. For example, colorectal CSCs with a marked potential to form distant metastasis are identified by CD26 and CD44v6 surface expression $[99,116]$ Further evidence for the unique role of CSCs in the metastatic process comes from the finding that cells expressing these markers (CD26 and CD44v6) can be isolated from the blood of CRC patients as circulating tumor cells (CTCs), and these cells display the ability to form cancers [117].

Unfortunately, the straight-forward idea of discriminating between CSCs and non-CSCs based on differential marker expression and clonogenic potential in xenotransplantation assays has proven to be opportunistic. Certain caveats are present, such as that using marker expression for CSC identification in many cases involves the use of proteins that directly facilitate grafting, e.g. CD44 [97, 118]. Secondly, similar to ISCs, the CSC state seems to be highly dynamic and partly installed by (micro-)environmental signals rather than a fate caused by intrinsic features [6]. Thirdly, the heterogeneous nature of malignancies is reflected in widespread heterogeneity between individual cancers of the same type, and even between clones, when CSC markers are considered [110, 119-121]. Furthermore, CSC marker expression is dynamic and therefore varies in time [122]. Critically, the xenotransplantation assays described above, solely capture CSC potential in an artificial manner as it requires disruption of tumor tissue. However, the process of tumor growth evidently relies on which cancer cells display clonogenic capacity within tumor tissue, so called CSC functionality, which has not been examined by using the transplantation assays. In the next section new techniques, i.e. (genetic) lineage tracing, are discussed that study CSC functionality in situ, which will ensure investigation of the dynamics of CSCs in tumor growth. 
This is important for further understanding of CRC in minimal residual disease, under therapeutic pressure and upon metastasizing to distant organs.

\section{Cancer stem cell functionality}

Strategies that involve (genetic) lineage tracing have been a widely used tool to study (stem) cell and clonal dynamics in different murine organs and their tissue-specific malignant counterparts [123]. However, the use of lineage tracing in human tissues and xenografts has been limited, as has the use of quantitative models of CSC-driven cancer growth. Conceptually dynamics of CSC populations are radically different than those of stem cells sustaining normal tissue homeostasis, as stem cells in cancer are an expanding population whilst in healthy organs the stem cell number remains constant. This notion has important implications for the models employed to describe the dynamics of the stem cell pool in cancers. Recently, we used a direct marker-free lineage tracing approach to investigate CSC functionality during short-term CRC outgrowth in an unbiased fashion [5]. Here, a clear heterogeneity in growth dynamics of the cancer cell pool was demonstrated within different tumor regions, e.g. cells located near the border or closer to the center. Strikingly, clonogenic outgrowth occurs mainly at the tumor border as opposed to the tumor center. Predictions of an accompanying mathematical model shows that the observed CSC dynamics can be attributed to (micro-)environmental regulation instead of cell-intrinsic features, thereby disregarding the strict hierarchical CSC theory (Fig. 3a). Additionally, in this model no correlation was found between CSC functionality and the CSC phenotype, as the presence of $\mathrm{Lgr} 5^{+}$cells was equally distributed throughout the whole tumor. In comparison, two other studies demonstrated that the $\mathrm{Lgr}^{+}$population represents the functional CSC pool compared to the more differentiated cell types [4, 100, 109]. However, spatiotemporal dynamics of these Lgr $^{+}$cells have not been specified. Another recent study highly supports the surface growth-driven model of CRC [124]. In this study neutral and stable multi-color labeling of CRC cells was employed to investigate the clonal outgrowth during the process of tumor growth. Strikingly, CRCs clearly show marked clonal outgrowth at the tumor edge in the whole process of CRC expansion and progression. These data also serve as an explanation for earlier observations from genetic barcoding studies [125-127]: Interestingly, these studies showed that upon clonal tracing in transplantation assays, different clones seem to either disappear or re-appear in serial transplants, which is an observation that often is attributed to the intrinsic CSC potential of cells. However, in agreement with the environment directed surface growth model, clones on the tumor border exhibit the greatest clonogenic potential due to their privileged location close to (micro-)environmental stimuli. However, when upon re-transplantation cells from smaller clones that have resided in non-privileged tumor sites extensively contribute to tumor growth, this does not reflect an intrinsic feature but simply more optimal environmental support. Evidently, studying CSCs and clonal dynamics in primary CRC in humans requires different approaches, as it is unethical to systematically observe tumor growth in patients. Techniques that infer clonal dynamics by taking advantage of neutral differences in the genomic composition of cells have been developed. For example, determining modifications in the metastable methylation pattern of CpG-rich genomic regions has proven to be a useful tool in CRC samples for this purpose as a measurement for the CSC fraction $[128,129]$. CSC estimations derived from these two studies were fairly dissimilar; one group inferred a functional CSC fraction of $1 \%$ from total population [129] whereas another group also speculated on a much higher incidence of functional CSCs [128]. Therefore, future studies that study the functional CSC compartment in human CRC would largely benefit for improved methods such as greater in-depth DNA sequencing or new lineage tracing tools based on neutral and stochastic genomic alterations [68].

\section{Cancer stem cells in therapy}

The frequent occurrence of therapy resistance remains one of the major clinical challenges for anti-CRC treatment. Multiple mechanisms underlie this therapy resistance for systemic therapies. Broadly, two main mechanisms have been described: genetic, either innate or acquired, and non-genetic mediated resistance [130]. CSCs are often held responsible for therapy resistance and indeed could provide an explanation for the observed non-genetic resistance patterns. In addition, CSCs provide an attractive explanation for the phenomenon of minimal residual disease in which seemingly effective therapy is followed by a remission due to the outgrowth of few surviving cancer cells [96]. Indeed, it was demonstrated that colorectal CSCs present with an increased resistance to conventional cytostatic agents [104, 131-134]. However, one major limitation in these pre-clinical studies is the phenotypic outcome measurements as interpretation for successful targeting of anti-tumor growth, e.g. investigation of reduced marker expression or Wnt signaling activity. Most likely this does not reflect the in situ CRC resistance. Nor does it provide information on the extent of therapy resistance of the clonogenic core of the cancer, i.e. the functional stem cell pool. Therefore, dedicated techniques that study the functional CSC compartment in space and time should be used to study CSC behavior upon therapeutic interventions. Examples of these 


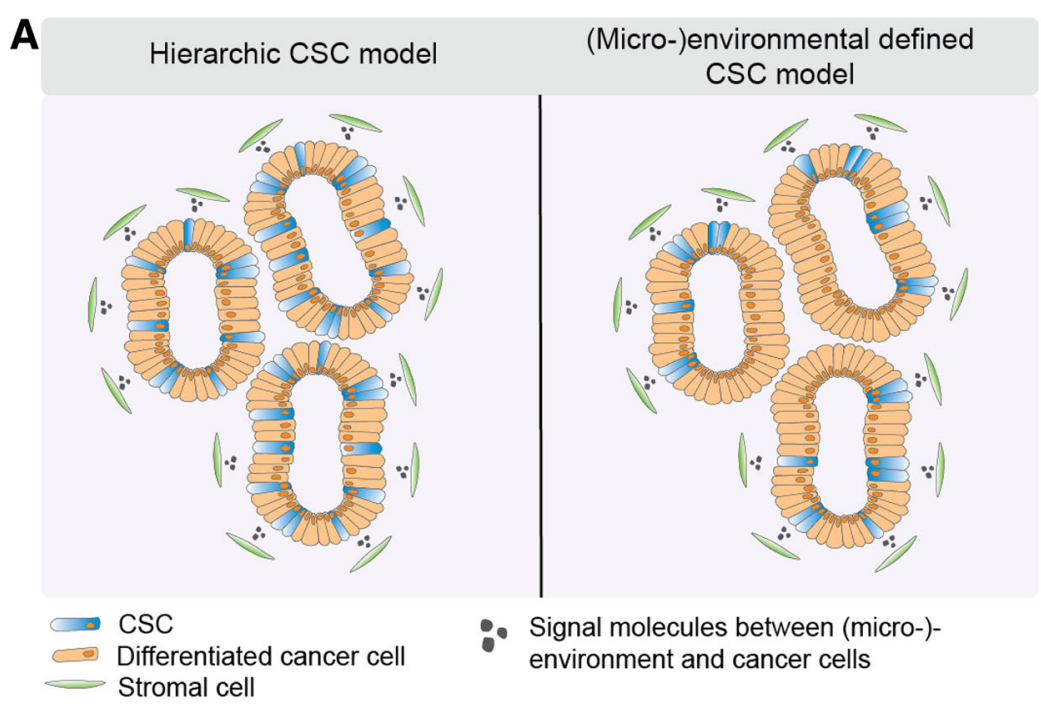

B

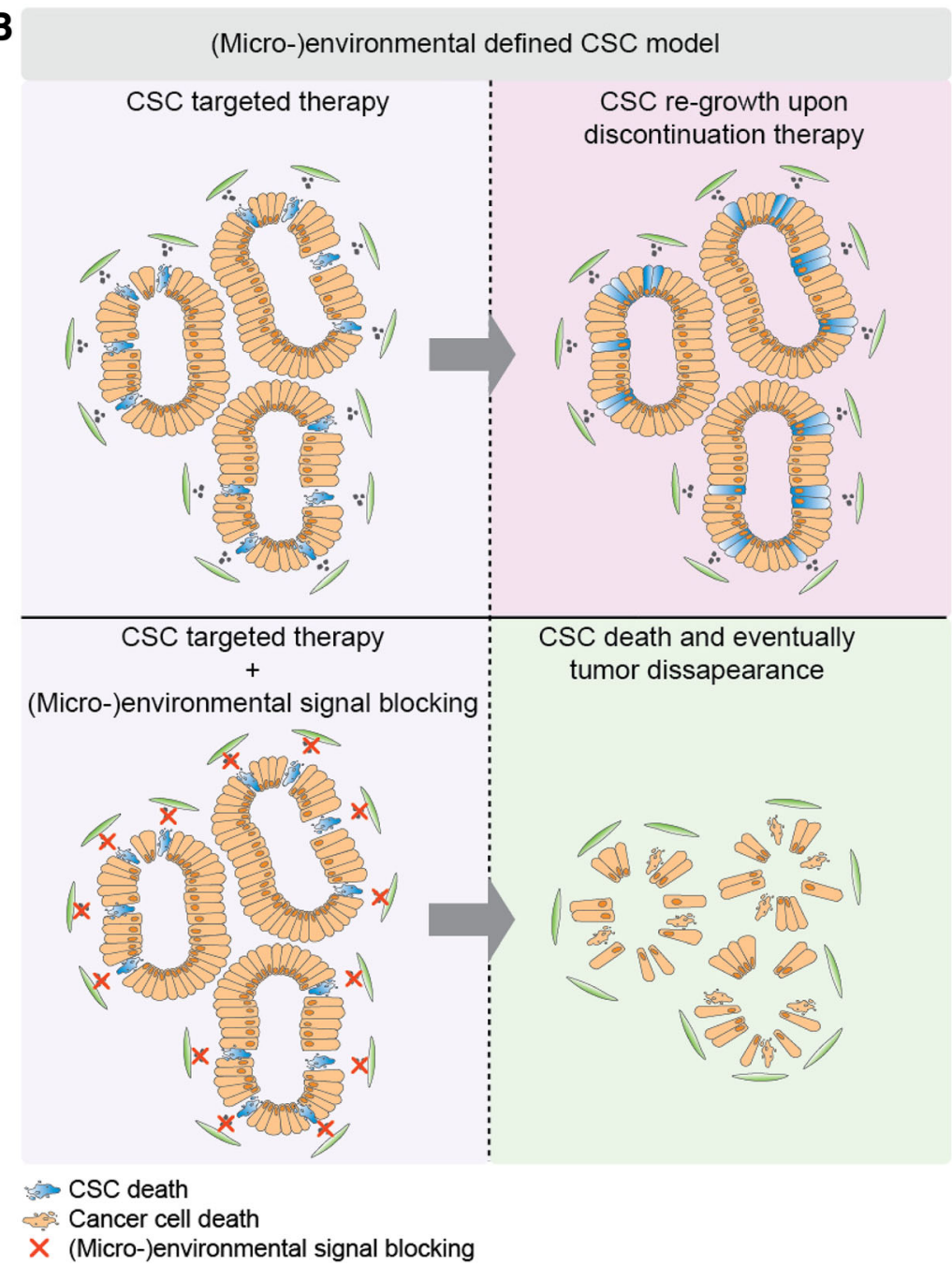

Fig. 3 (See legend on next page.) 


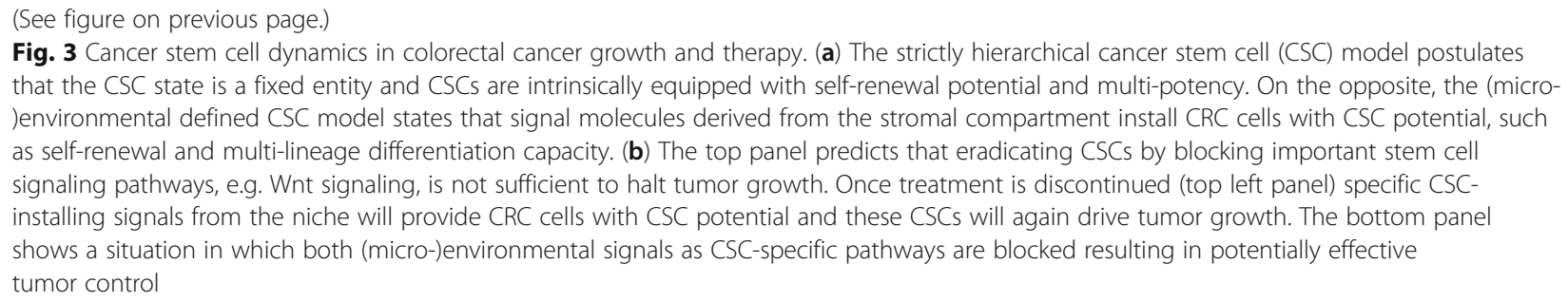

methods include serial passaging of xenograft material, assessment of metastatic capacity and the ability to drive regrowth of cancers after therapy cessation. In addition, specific measurement of clonogenic potential in situ of treated cells using lineage tracing strategies is feasible [5].

Various different characteristics are designated to CSCs that are thought to be important for their resistant phenotype. One example is the predicted dependence of CSCs on highly conserved signaling transduction pathways that are also involved in normal stem cell biology $[6,135]$. These pathways include for example Wnt, Notch and Hedgehog $(\mathrm{HH})$. Therefore, one approach as anti-CSC strategy is to inhibit these pathways. For example, in case of CRC compounds that directly inhibit the Wnt pathway or target the Wnt ${ }^{\text {high }}$ cells have been generated. In xenograft studies it was shown that specifically targeting the $\mathrm{Lgr}^{+}$cells through antibody-drug conjugated therapy, or directly genetically, indeed inhibits tumor growth without affecting intestinal epithelium homeostasis $[4,136,137]$. Also, other upstream Wnt pathway inhibiting agents have been described to halt tumor growth in preclinical models [138, 139]. Several clinical trials are currently running to test the effect of CSC interference on tumor growth. For CRC, these inhibitors include the upstream Wnt-signaling targets, e.g. PORCN and anti-RSPO3 [140]. Critically, the methods used to determine treatment responses are often criticized as these are solely based on the outcome of surrogate parameters, e.g. radiological tumor response in early phase trials. Yet, similar to preclinical studies, it would be crucial to measure the therapeutic effects on specifically the (functional) CSC compartment.

In addition, potentially multiple other factors complicate the efficacy of anti-CSC treatment in patients. For example, differential therapy responses might occur depending on the location of the CSCs, either in (loco-)regional or hematogenous metastasized CRC. Namely, CSC activity and functionality might differ depending on which environmental stimuli these cells receive from their tumor niche [4]. Interestingly, the $\mathrm{Wnt}^{\text {high }}$ cell population is found responsible for metastasis to distant organ sites such as the liver [4]. This indicates that targeting the Wnt pathway could be beneficial for preventing metastasis. Importantly, most (pre-)clinical trials are performed in patients that already have metastatic disease. Furthermore, it is conceivable that inhibiting the Wnt signaling cascade is unpromising as the tumor niche and its crosstalk with tumor cells mediates dedifferentiation of non-CSCs. This implies that replenishment of the CSC pool still occurs when CSCs are targeted but not (micro-)environmental stimulated dedifferentiation of other CRC cells (Fig. 3b). Ideally, an approach with combined treatment of inhibiting tumor-niche signals installing the CSC state and a direct anti-CSC target would be essential (Fig. 3b). An example of targeting the Wnt agonizing stimuli from the (micro-)environment would be to block the MET receptor, preventing activation by myofibroblast-derived HGF $[141,142]$. Interestingly, one study found that monotherapy with targeting the Wnt ${ }^{\text {high }}$ CRC cells in liver metastasis was sufficient to prevent re-growth of tumors [4]. This indicates that different organs provide for distinct tumor niches which impacts on the extent of CRC cell plasticity. Another phenomenon that might hamper effective anti-CRC treatment is the stochastic phenotypic state switching events of tumor cells. For breast cancer it was found that in vitro the cancer cell population was stably displaying a constant phenotypic equilibrium, even upon isolation and expansion of distinct subpopulations [143]. This suggests that cancer cells are subjected to stochastic (de-)differentiation, even without the interference of (micro-)environmental stimuli. This mechanism of stochastic transitioning between differentiation states of tumor cells, in addition to (micro-)environmental mediated CSC plasticity, might be a major contributor to therapy resistance, which at present is complicating the efficacy of anti-CRC therapies.

\section{Conclusions}

Clearly, intestinal homeostasis is a much better understood process than the dynamics that underlie CRC formation and growth. However, also for the normal intestinal epithelium critical unsolved issues remain to be answered. For example, it is still unknown to which degree intestinal cellular plasticity takes place and whether all intestinal epithelial cells are able to undergo such events. Similar to the normal intestinal epithelium, for CRC it has been recognized that a cellular hierarchy 
is present [97]. Also, it is apparent that CRC progression, which relies on CSC activity, does not simply depend on the mutational profile of tumor cells within different clones or tumors. Particularly, it is proposed that CSC activity is coordinated by the niche and possibly stochastic events instead of intrinsic regulatory mechanisms [5, 124, 143]. Evidently, CRC cells are involved in a dynamic interplay with their niche, and interact through the modification of multiple signaling pathways that are yet partly unknown. Identification of the key players that provoke CSC activity in CRC cells will be crucial. In addition, we and others in the field raise critical concerns about the predicted effectiveness of strategies to cure CRC that solely target intrinsic stem cell features [140, 144]. Furthermore, (micro-)environmental regulation of tumor cells might also depend on the organ specific environment [4], which potentially will complicate the development of suitable therapies. Another hurdle is the potential heterogeneity of the stromal compartment among different CRC subtypes, which would require different approaches for abrogating stroma-tumor interactions [9]. Future studies should be directed towards gaining a better understanding of CSCs behavior in human tumor growth and upon therapy responses, with the emphasis on studying CSC dynamics in their native environment. These insights will be crucial for developing new strategies to more effectively treat this disease.

\section{Abbreviations \\ APC: Adenomatous polyposis coli; Bmi1: B lymphoma Mo-MLV insertion re- gion 1 homolog; BMP: Bone morphogenetic protein; CRC: Colorectal cancer; CSC: Cancer stem cell; Dclk1: Doublecortin-like kinase 1; DII1: Delta-like 1; DII4: Delta-like 4; EGF: Epithelial growth factor; HGF: Hepatocyte growth factor; HH: Hedgehog; Hopx: HOP homeobox; ISC: Intestinal stem cell; Lgr5: Leucine-rich-repeat-containing G-protein-coupled receptor 5; LRC: Label-retaining cell; Lrig1: Leucine Rich Repeats And Immunoglobulin Like Domains 1; mTert: Mouse telomerase reverse transcriptase; Nf- KB: nuclear factor-KB; Prom1: Prominin 1; Smoc2: SPARC related modular calcium binding 2; Sox9: SRY-box 9; TGF-a: Transforming growth factor-a}

\section{Acknowledgments}

Not applicable.

\section{Funding}

This work was supported by the Amsterdam UMC (Academic Medical Center), The New York Stem Cell Foundation, and grants from KWF (UVA2011-4969, UVA2014-7245 and 10529), the Maag Lever Darm Stichting (MLDS-CDG 14-03), the European Research Council (ERG-StG 638193) and ZonMw (Vidi 016.156.308) to L.V. L.V. is a New York Stem Cell FoundationRobertson Investigator.

\section{Availability of data and materials}

Data sharing is not applicable to this review, as no datasets have been generated.

\section{Authors' contributions}

Both authors have contributed equally to the writing process of this manuscript. Both authors read and approved the final manuscript.

Ethics approval and consent to participate Not applicable.
Consent for publication

Not applicable.

\section{Competing interests}

The authors declare that they have no competing interests.

\section{Publisher's Note}

Springer Nature remains neutral with regard to jurisdictional claims in published maps and institutional affiliations.

Received: 27 December 2018 Accepted: 20 February 2019 Published online: 30 March 2019

\section{References}

1. Siegel RL, Miller KD, Fedewa SA, Ahnen DJ, Meester RGS, Barzi A, et al. Colorectal cancer statistics, 2017. CA Cancer J Clin. 2017;67(3):177-93.

2. Hanahan D, Weinberg RA. The hallmarks of cancer. Cell. 2000;100(1):57-70.

3. Fearon $E R$, Vogelstein B. A genetic model for colorectal tumorigenesis. Cell. 1990;61(5):759-67.

4. de Sousa e Melo F, Kurtova AV, Harnoss JM, Kljavin N, Hoeck JD, Hung J, et al. A distinct role for $\operatorname{Lgr} 5(+)$ stem cells in primary and metastatic colon cancer. Nature. 2017:543(7647):676-680.

5. Lenos KJ, Miedema DM, Lodestijn SC, Nijman LE, van den Bosch T, Romero Ros $X$, et al. Stem cell functionality is microenvironmentally defined during tumour expansion and therapy response in colon cancer. Nat Cell Biol. 2018:20(10):1193-202.

6. Vermeulen L, De Sousa EMF, van der Heijden M, Cameron K, de Jong JH, Borovski T, et al. Wnt activity defines colon cancer stem cells and is regulated by the microenvironment. Nat Cell Biol 2010;12(5):468-476.

7. De Sousa EMF, Vermeulen L, Fessler E, Medema JP. Cancer heterogeneity--a multifaceted view. EMBO Rep 2013;14(8):686-695.

8. Linnekamp JF, Wang X, Medema JP, Vermeulen L. Colorectal cancer heterogeneity and targeted therapy: a case for molecular disease subtypes. Cancer Res. 2015;75(2):245-9.

9. De Sousa EMF, Wang X, Jansen M, Fessler E, Trinh A, de Rooij LP, et al. Poorprognosis colon cancer is defined by a molecularly distinct subtype and develops from serrated precursor lesions. Nat Med 2013:19(5):614-618

10. Guinney J, Dienstmann R, Wang X, de Reynies A, Schlicker A, Soneson C, et al. The consensus molecular subtypes of colorectal cancer. Nat Med. 2015;21(11):1350-6.

11. Barker N, Ridgway RA, van Es $J H$, van de Wetering $M$, Begthel $H$, van den Born $\mathrm{M}$, et al. Crypt stem cells as the cells-of-origin of intestinal cancer. Nature. 2009:457(7229):608-11.

12. Bjerknes $\mathrm{M}$, Cheng $\mathrm{H}$. Clonal analysis of mouse intestinal epithelial progenitors. Gastroenterology. 1999;116(1):7-14.

13. Clevers $\mathrm{H}$. The intestinal crypt, a prototype stem cell compartment. Cell. 2013;154(2):274-84.

14. Barker N, van Es JH, Kuipers J, Kujala P, van den Born M, Cozijnsen M, et al. Identification of stem cells in small intestine and colon by marker gene Lgr5. Nature. 2007;449(7165):1003-7.

15. Cheng $\mathrm{H}$, Leblond $\mathrm{CP}$. Origin, differentiation and renewal of the four main epithelial cell types in the mouse small intestine. I Columnar cell Am J Anat 1974;141(4):461-479.

16. Cheng $H$, Leblond $C P$. Origin, differentiation and renewal of the four main epithelial cell types in the mouse small intestine. V. Unitarian theory of the origin of the four epithelial cell types. Am J Anat. 1974;141(4):537-61.

17. Sangiorgi $E$, Capecchi MR. Bmi1 is expressed in vivo in intestinal stem cells. Nat Genet. 2008:40(7):915-20.

18. Takeda N, Jain R, LeBoeuf MR, Wang Q, Lu MM, Epstein JA. Interconversion between intestinal stem cell populations in distinct niches. Science. 2011; 334(6061):1420-1424.

19. Munoz J, Stange DE, Schepers AG, van de Wetering M, Koo BK, Itzkovitz S, et al. The Lgr5 intestinal stem cell signature: robust expression of proposed quiescent '+4' cell markers. EMBO J. 2012;31(14):3079-91.

20. Montgomery RK, Carlone DL, Richmond CA, Farilla L, Kranendonk ME, Henderson DE, et al. Mouse telomerase reverse transcriptase (mTert) expression marks slowly cycling intestinal stem cells. Proc Natl Acad Sci U S A 2011;108(1):179-184.

21. van der Flier $L G$, van Gijn ME, Hatzis P, Kujala P, Haegebarth A, Stange DE, et al. Transcription factor achaete scute-like 2 controls intestinal stem cell fate. Cell. 2009;136(5):903-12. 
22. Powell AE, Wang Y, Li Y, Poulin EJ, Means AL, Washington MK, et al. The pan-ErbB negative regulator Lrig1 is an intestinal stem cell marker that functions as a tumor suppressor. Cell. 2012;149(1):146-58.

23. Zhu L, Gibson P, Currle DS, Tong Y, Richardson RJ, Bayazitov IT, et al. Prominin 1 marks intestinal stem cells that are susceptible to neoplastic transformation. Nature. 2009;457(7229):603-7.

24. Snippert HJ, van Es JH, van den Born M, Begthel H, Stange DE, Barker N, et al. Prominin-1/CD133 marks stem cells and early progenitors in mouse small intestine. Gastroenterology. 2009;136(7):2187-2194 e1.

25. Sato $T$, van Es $J H$, Snippert HJ, Stange DE, Vries RG, van den Born M, et al. Paneth cells constitute the niche for Lgr5 stem cells in intestinal crypts. Nature. 2011;469(7330):415-8.

26. Baker AM, Cereser B, Melton S, Fletcher AG, Rodriguez-Justo M, Tadrous PJ et al. Quantification of crypt and stem cell evolution in the normal and neoplastic human colon. Cell Rep. 2014;8(4):940-7.

27. Lopez-Garcia C, Klein AM, Simons BD, Winton DJ. Intestinal stem cell replacement follows a pattern of neutral drift. Science. 2010;330(6005):822-5.

28. Snippert HJ, van der Flier LG, Sato T, van Es JH, van den Born M, KroonVeenboer C, et al. Intestinal crypt homeostasis results from neutral competition between symmetrically dividing Lgr5 stem cells. Cell. 2010; 143(1):134-44.

29. Ritsma L, Ellenbroek SIJ, Zomer A, Snippert HJ, de Sauvage FJ, Simons BD, et al. Intestinal crypt homeostasis revealed at single-stem-cell level by in vivo live imaging. Nature. 2014;507(7492):362-5.

30. Kozar S, Morrissey E, Nicholson AM, van der Heijden M, Zecchini HI, Kemp R, et al. Continuous clonal labeling reveals small numbers of functional stem cells in intestinal crypts and adenomas. Cell Stem Cell. 2013;13(5):626-33.

31. Tian $H$, Biehs $B$, Warming $S$, Leong $K G$, Rangell $L$, Klein OD, et al. A reserve stem cell population in small intestine renders Lgr5-positive cells dispensable. Nature. 2011;478(7368):255-9.

32. Metcalfe C, Kljavin NM, Ybarra R, de Sauvage FJ. Lgr5+ stem cells are indispensable for radiation-induced intestinal regeneration. Cell Stem Cell. 2014;14(2):149-59.

33. Tetteh PW, Basak O, Farin HF, Wiebrands K, Kretzschmar K, Begthel H, et al. Replacement of lost Lgr5-positive stem cells through plasticity of their enterocyte-lineage daughters. Cell Stem Cell. 2016;18(2):203-13.

34. van Es JH, Sato T, van de Wetering M, Lyubimova A, Nee AN, Gregorieff A, et al. Dll1+ secretory progenitor cells revert to stem cells upon crypt damage. Nat Cell Biol 2012;14(10):1099-1104.

35. Tomic G, Morrissey E, Kozar S, Ben-Moshe S, Hoyle A, Azzarelli R, et al. Phospho-regulation of ATOH1 is required for plasticity of secretory progenitors and tissue regeneration. Cell Stem Cell. 2018.

36. Asfaha S, Hayakawa Y, Muley A, Stokes S, Graham TA, Ericksen RE, et al. Krt19(+)/Lgr5(-) cells are Radioresistant Cancer-initiating stem cells in the Colon and Intestine. Cell Stem Cell. 2015;16(6):627-38.

37. Barriga FM, Montagni E, Mana M, Mendez-Lago M, Hernando-Momblona X, Sevillano M, et al. Mex3a Marks a slowly dividing subpopulation of Lgr5+ intestinal stem cells. Cell Stem Cell 2017;20(6):801-816 e7.

38. Vermeulen L, Snippert HJ. Stem cell dynamics in homeostasis and cancer of the intestine. Nat Rev Cancer. 2014;14(7):468-80.

39. Buczacki SJ, Zecchini HI, Nicholson AM, Russell R, Vermeulen L, Kemp R, et al. Intestinal label-retaining cells are secretory precursors expressing Lgr5. Nature. 2013;495(7439):65-69.

40. Jadhav U, Saxena M, O'Neill NK, Saadatpour A, Yuan GC, Herbert Z, et al. Dynamic reorganization of chromatin accessibility signatures during dedifferentiation of secretory precursors into Lgr5+ intestinal stem cells. Cell Stem Cell 2017:21(1):65-77 e5.

41. Kaaij LT, van de Wetering M, Fang F, Decato B, Molaro A, van de Werken $\mathrm{HJ}$, et al. DNA methylation dynamics during intestinal stem cell differentiation reveals enhancers driving gene expression in the villus. Genome Biol 2013; 14(5):R50.

42. Kim TH, Li F, Ferreiro-Neira I, Ho LL, Luyten A, Nalapareddy K, et al. Broadly permissive intestinal chromatin underlies lateral inhibition and cell plasticity. Nature. 2014;506(7489):511-5.

43. Yan KS, Gevaert O, Zheng GXY, Anchang B, Probert CS, Larkin KA, et al. Intestinal Enteroendocrine lineage cells possess homeostatic and injuryinducible stem cell activity. Cell Stem Cell 2017;21(1):78-90 e6.

44. Schmitt M, Schewe M, Sacchetti A, Feijtel D, van de Geer WS, Teeuwssen M, et al. Paneth cells respond to inflammation and contribute to tissue regeneration by acquiring stem-like features through SCF/c-kit signaling. Cell Rep 2018;24(9):2312-2328 e7.
45. Yu S, Tong K, Zhao Y, Balasubramanian I, Yap GS, Ferraris RP, et al. Paneth cell multipotency induced by notch activation following injury. Cell Stem Cell 2018;23(1):46-59 e5.

46. Voog J, Jones DL. Stem cells and the niche: a dynamic duo. Cell Stem Cell. 2010;6(2):103-15.

47. Korinek V, Barker N, Moerer P, van Donselaar E, Huls G, Peters PJ, et al. Depletion of epithelial stem-cell compartments in the small intestine of mice lacking Tcf-4. Nat Genet. 1998;19(4):379-83.

48. Farin HF, Van Es JH, Clevers $H$. Redundant sources of Wnt regulate intestinal stem cells and promote formation of Paneth cells. Gastroenterology. 2012; 143(6):1518-1529 e7.

49. Valenta T, Degirmenci B, Moor AE, Herr P, Zimmerli D, Moor MB, et al. Wnt ligands secreted by subepithelial mesenchymal cells are essential for the survival of intestinal stem cells and gut homeostasis. Cell Rep. 2016;15(5): 911-8.

50. Shoshkes-Carmel M, Wang YJ, Wangensteen KJ, Toth B, Kondo A, Massasa $\mathrm{EE}$, et al. Subepithelial telocytes are an important source of Wnts that supports intestinal crypts. Nature. 2018;557(7704):242-6.

51. Wong W, Stange DE, Page ME, Buczacki S, Wabik A, Itami S, et al. Lrig1 controls intestinal stem-cell homeostasis by negative regulation of ErbB signalling. Nat Cell Biol 2012;14(4):401-408.

52. Haramis AP, Begthel $H$, van den Born M, van Es J, Jonkheer S, Offerhaus GJ, et al. De novo crypt formation and juvenile polyposis on BMP inhibition in mouse intestine. Science. 2004;303(5664):1684-6.

53. Kosinski C, Li VS, Chan AS, Zhang J, Ho C, Tsui WY, et al. Gene expression patterns of human colon tops and basal crypts and BMP antagonists as intestinal stem cell niche factors. Proc Natl Acad Sci U S A 2007;104(39): 15418-15423.

54. Spit M, Koo BK, Maurice MM. Tales from the crypt: intestinal niche signals in tissue renewal, plasticity and cancer. Open Biol. 2018;8(9).

55. Howe JR, Bair JL, Sayed MG, Anderson ME, Mitros FA, Petersen GM, et al. Germline mutations of the gene encoding bone morphogenetic protein receptor 1A in juvenile polyposis. Nat Genet. 2001;28(2):184-7.

56. He XC, Zhang J, Tong WG, Tawfik O, Ross J, Scoville DH, et al. BMP signaling inhibits intestinal stem cell self-renewal through suppression of Wnt-betacatenin signaling. Nat Genet 2004;36(10):1117-1121.

57. Pellegrinet L, Rodilla V, Liu Z, Chen S, Koch U, Espinosa L, et al. Dll1- and dll4-mediated notch signaling are required for homeostasis of intestinal stem cells. Gastroenterology. 2011;140(4):1230-40 e1-7.

58. van Es JH, van Gijn ME, Riccio O, van den Born M, Vooijs M, Begthel $H$, et al. Notch/gamma-secretase inhibition turns proliferative cells in intestinal crypts and adenomas into goblet cells. Nature. 2005:435(7044):959-63.

59. Yang Q, Bermingham NA, Finegold MJ, Zoghbi HY. Requirement of Math1 for secretory cell lineage commitment in the mouse intestine. Science. 2001;294(5549):2155-8.

60. Basak O, Beumer J, Wiebrands K, Seno H, van Oudenaarden A, Clevers H. Induced quiescence of Lgr5+ stem cells in intestinal organoids enables differentiation of hormone-producing Enteroendocrine cells. Cell Stem Cell 2017;20(2):177-190 e4

61. Beumer J, Artegiani B, Post Y, Reimann F, Gribble F, Nguyen TN, et al. Enteroendocrine cells switch hormone expression along the crypt-to-villus BMP signalling gradient. Nat Cell Biol. 2018;20(8):909-16.

62. Rothenberg ME, Nusse Y, Kalisky T, Lee JJ, Dalerba P, Scheeren F, et al. Identification of a cKit(+) colonic crypt base secretory cell that supports Lgr5(+) stem cells in mice. Gastroenterology. 2012;142(5):1195-1205 e6.

63. Sasaki N, Sachs N, Wiebrands K, Ellenbroek SI, Fumagalli A, Lyubimova A, et al. Reg4+ deep crypt secretory cells function as epithelial niche for Lgr5+ stem cells in colon. Proc Natl Acad Sci U S A 2016;113(37):E5399-E5407.

64. Degirmenci B, Valenta T, Dimitrieva S, Hausmann G, Basler K. GLI1expressing mesenchymal cells form the essential Wnt-secreting niche for colon stem cells. Nature. 2018:558(7710):449-53.

65. Jung P, Sato T, Merlos-Suarez A, Barriga FM, Iglesias M, Rossell D, et al. Isolation and in vitro expansion of human colonic stem cells. Nat Med. 2011;17(10):1225-7.

66. Yui S, Nakamura T, Sato T, Nemoto Y, Mizutani T, Zheng X, et al. Functional engraftment of colon epithelium expanded in vitro from a single adult Lgr5(+) stem cell. Nat Med. 2012;18(4):618-23.

67. Hirata A, Utikal J, Yamashita S, Aoki H, Watanabe A, Yamamoto T, et al. Dose-dependent roles for canonical Wnt signalling in de novo crypt formation and cell cycle properties of the colonic epithelium. Development. 2013;140(1):66-75 
68. Nicholson AM, Olpe C, Hoyle A, Thorsen AS, Rus T, Colombe M, et al. Fixation and spread of somatic mutations in adult human colonic epithelium. Cell Stem Cell 2018;22(6):909-918 e8.

69. Visvader JE. Cells of origin in cancer. Nature. 2011;469(7330):314-22.

70. Shih IM, Wang TL, Traverso G, Romans K, Hamilton SR, Ben-Sasson S, et al. Top-down morphogenesis of colorectal tumors. Proc Natl Acad Sci U S A. 2001;98(5):2640-5.

71. Logan CY, Nusse R. The Wnt signaling pathway in development and disease. Annu Rev Cell Dev Biol. 2004;20:781-810.

72. Shibata H, Toyama K, Shioya H, Ito M, Hirota M, Hasegawa S, et al. Rapid colorectal adenoma formation initiated by conditional targeting of the Apc gene. Science. 1997;278(5335):120-3.

73. Schwitalla S, Fingerle AA, Cammareri P, Nebelsiek T, Goktuna SI, Ziegler PK, et al. Intestinal tumorigenesis initiated by dedifferentiation and acquisition of stem-cell-like properties. Cell. 2013;152(1-2):25-38.

74. van der Heijden M, Zimberlin CD, Nicholson AM, Colak S, Kemp R, Meijer SL, et al. $\mathrm{BCl}-2$ is a critical mediator of intestinal transformation. Nat Commun. 2016;7:10916.

75. Westphalen CB, Asfaha S, Hayakawa Y, Takemoto Y, Lukin DJ, Nuber AH, et al. Long-lived intestinal tuft cells serve as colon cancer-initiating cells. J Clin Invest. 2014;124(3):1283-95

76. Nakanishi Y, Seno H, Fukuoka A, Ueo T, Yamaga Y, Maruno T, et al. Dclk1 distinguishes between tumor and normal stem cells in the intestine. Nat Genet. 2013;45(1):98-103

77. Jess T, Rungoe C, Peyrin-Biroulet L. Risk of colorectal cancer in patients with ulcerative colitis: a meta-analysis of population-based cohort studies. Clin Gastroenterol Hepatol 2012:10(6):639-645.

78. Jansen M, Langeveld D, De Leng WW, Milne AN, Giardiello FM, Offerhaus GJ. LKB1 as the ghostwriter of crypt history. Familial Cancer 2011;10(3):437-446.

79. Arber N, Eagle CJ, Spicak J, Racz I, Dite P, Hajer J, et al. Celecoxib for the prevention of colorectal adenomatous polyps. N Engl J Med. 2006;355(9): 885-95.

80. Rothwell PM, Fowkes FG, Belch JF, Ogawa H, Warlow CP, Meade TW. Effect of daily aspirin on long-term risk of death due to cancer: analysis of individual patient data from randomised trials. Lancet. 2011;377(9759):31-41.

81. Phillips RK, Wallace MH, Lynch PM, Hawk E, Gordon GB, Saunders BP, et al. A randomised, double blind, placebo controlled study of celecoxib, a selective cyclooxygenase 2 inhibitor, on duodenal polyposis in familial adenomatous polyposis. Gut. 2002;50(6):857-60.

82. Cuzick J, Otto F, Baron JA, Brown PH, Burn J, Greenwald P, et al. Aspirin and non-steroidal anti-inflammatory drugs for cancer prevention: an international consensus statement. Lancet Oncol. 2009;10(5):501-7.

83. Vermeulen L, Morrissey E, van der Heijden M, Nicholson AM, Sottoriva A, Buczacki $S$, et al. Defining stem cell dynamics in models of intestinal tumor initiation. Science. 2013;342(6161):995-8.

84. Snippert HJ, Schepers AG, van Es JH, Simons BD, Clevers H. Biased competition between Lgr5 intestinal stem cells driven by oncogenic mutation induces clonal expansion. EMBO Rep. 2014;15(1):62-9.

85. Bruens L, Ellenbroek SIJ, van Rheenen J, Snippert HJ. In vivo imaging reveals existence of crypt fission and fusion in adult mouse intestine. Gastroenterology. 2017;153(3):674-677 e3.

86. Cairnie $A B$, Millen $B H$. Fission of crypts in the small intestine of the irradiated mouse. Cell Tissue Kinet. 1975;8(2):189-96.

87. Cheng H, Bjerknes M, Amar J, Gardiner G. Crypt production in normal and diseased human colonic epithelium. Anat Rec. 1986;216(1):44-8.

88. Graham TA, Humphries A, Sanders T, Rodriguez-Justo M, Tadrous PJ, Preston $\mathrm{SL}$, et al. Use of methylation patterns to determine expansion of stem cell clones in human colon tissue. Gastroenterology. 2011;140(4):1241-50 e1-9.

89. Greaves LC, Preston SL, Tadrous PJ, Taylor RW, Barron MJ, Oukrif D, et al. Mitochondrial DNA mutations are established in human colonic stem cells, and mutated clones expand by crypt fission. Proc Natl Acad Sci U S A. 2006; 103(3):714-9.

90. Leedham SJ, Graham TA, Oukrif D, McDonald SA, Rodriguez-Justo M, Harrison RF, et al. Clonality, founder mutations, and field cancerization in human ulcerative colitis-associated neoplasia. Gastroenterology. 2009;136(2): 542-550 e6.

91. Stryker SJ, Wolff BG, Culp CE, Libbe SD, Ilstrup DM, MacCarty RL. Natural history of untreated colonic polyps. Gastroenterology. 1987;93(5):1009-1013.

92. Schepers $A G$, Snippert HJ, Stange DE, van den Born M, van Es JH, van de Wetering $M$, et al. Lineage tracing reveals Lgr $5+$ stem cell activity in mouse intestinal adenomas. Science. 2012;337(6095):730-5.
93. Humphries A, Cereser B, Gay LJ, Miller DS, Das B, Gutteridge A, et al. Lineage tracing reveals multipotent stem cells maintain human adenomas and the pattern of clonal expansion in tumor evolution. Proc Natl Acad Sci U S A 2013;110(27):E2490-E2499.

94. van den Brink GR, Offerhaus GJ. The morphogenetic code and colon cancer development. Cancer Cell. 2007;11(2):109-17.

95. Wong WM, Mandir N, Goodlad RA, Wong BC, Garcia SB, Lam SK, et al. Histogenesis of human colorectal adenomas and hyperplastic polyps: the role of cell proliferation and crypt fission. Gut. 2002;50(2):212-7.

96. Vermeulen L, de Sousa e Melo F, Richel DJ, Medema JP. The developing cancer stem-cell model: clinical challenges and opportunities. Lancet Oncol. 2012;13(2):e83-e89.

97. Vermeulen L, Sprick MR, Kemper K, Stassi G, Medema JP. Cancer stem cells-old concepts, new insights. Cell Death Differ. 2008;15(6):947-58.

98. Vermeulen L, Todaro M, de Sousa Mello F, Sprick MR, Kemper K, Perez Alea $M$, et al. Single-cell cloning of colon cancer stem cells reveals a multilineage differentiation capacity. Proc Natl Acad Sci U S A 2008;105(36): 13427-13432.

99. Todaro M, Gaggianesi M, Catalano V, Benfante A, lovino F, Biffoni M, et al. CD44v6 is a marker of constitutive and reprogrammed cancer stem cells driving colon cancer metastasis. Cell Stem Cell. 2014;14(3):342-56.

100. Shimokawa M, Ohta Y, Nishikori S, Matano M, Takano A, Fujii M, et al. Visualization and targeting of LGR5+ human colon cancer stem cells. Nature. 2017

101. Calon A, Espinet E, Palomo-Ponce S, Tauriello DV, Iglesias M, Cespedes MV, et al. Dependency of colorectal cancer on a TGF-beta-driven program in stromal cells for metastasis initiation. Cancer Cell 2012;22(5):571-584.

102. Yusra, Semba S, Yokozaki H. Biological significance of tumor budding at the invasive front of human colorectal carcinoma cells. Int J Oncol 2012:41(1): 201-210.

103. Zubeldia IG, Bleau AM, Redrado M, Serrano D, Agliano A, Gil-Puig C, et al. Epithelial to mesenchymal transition and cancer stem cell phenotypes leading to liver metastasis are abrogated by the novel TGFbeta1-targeting peptides P17 and P144. Exp Cell Res 2013;319(3):12-22.

104. Lotti F, Jarrar AM, Pai RK, Hitomi M, Lathia J, Mace A, et al. Chemotherapy activates cancer-associated fibroblasts to maintain colorectal cancerinitiating cells by IL-17A. J Exp Med. 2013;210(13):2851-72.

105. Bonnet D, Dick JE. Human acute myeloid leukemia is organized as a hierarchy that originates from a primitive hematopoietic cell. Nat Med. 1997;3(7):730-7.

106. Lapidot T, Sirard C, Vormoor J, Murdoch B, Hoang T, Caceres-Cortes J, et al. A cell initiating human acute myeloid leukaemia after transplantation into SCID mice. Nature. 1994;367(6464):645-8.

107. Al-Hajj M, Wicha MS, Benito-Hernandez A, Morrison SJ, Clarke MF. Prospective identification of tumorigenic breast cancer cells. Proc Natl Acad Sci U S A. 2003;100(7):3983-8.

108. Singh SK, Hawkins C, Clarke ID, Squire JA, Bayani J, Hide T, et al. Identification of human brain tumour initiating cells. Nature. 2004;432(7015): 396-401.

109. Cortina C, Turon G, Stork D, Hernando-Momblona X, Sevillano M, Aguilera $M$, et al. A genome editing approach to study cancer stem cells in human tumors. EMBO Mol Med. 2017;9(7):869-79.

110. Dalerba P, Dylla SJ, Park IK, Liu R, Wang X, Cho RW, et al. Phenotypic characterization of human colorectal cancer stem cells. Proc Natl Acad Sci U S A. 2007;104(24):10158-63.

111. Huang EH, Hynes MJ, Zhang T, Ginestier C, Dontu G, Appelman H, et al. Aldehyde dehydrogenase 1 is a marker for normal and malignant human colonic stem cells (SC) and tracks SC overpopulation during colon tumorigenesis. Cancer Res. 2009;69(8):3382-9.

112. Kemper K, Prasetyanti PR, De Lau W, Rodermond H, Clevers H, Medema JP. Monoclonal antibodies against Lgr5 identify human colorectal cancer stem cells. Stem Cells. 2012;30(11):2378-86.

113. Merlos-Suarez A, Barriga FM, Jung P, Iglesias M, Cespedes MV, Rossell D, et al. The intestinal stem cell signature identifies colorectal cancer stem cells and predicts disease relapse. Cell Stem Cell. 2011;8(5):511-24.

114. O'Brien CA, Pollett A, Gallinger S, Dick JE. A human colon cancer cell capable of initiating tumour growth in immunodeficient mice. Nature. 2007; 445(7123):106-110.

115. Ricci-Vitiani L, Lombardi DG, Pilozzi E, Biffoni M, Todaro M, Peschle C, et al. Identification and expansion of human colon-cancer-initiating cells. Nature. 2007;445(7123):111-5. 
116. Pang R, Law WL, Chu AC, Poon JT, Lam CS, Chow AK, et al. A subpopulation of CD26+ cancer stem cells with metastatic capacity in human colorectal cancer. Cell Stem Cell 2010;6(6):603-615

117. Grillet F, Bayet E, Villeronce O, Zappia L, Lagerqvist EL, Lunke $S$, et al. Circulating tumour cells from patients with colorectal cancer have cancer stem cell hallmarks in ex vivo culture. Gut. 2017:66(10):1802-10.

118. Orian-Rousseau V. CD44, a therapeutic target for metastasising tumours. Eur J Cancer. 2010;46(7):1271-7.

119. Ginestier C, Hur MH, Charafe-Jauffret E, Monville F, Dutcher J, Brown M, et al. ALDH1 is a marker of normal and malignant human mammary stem cells and a predictor of poor clinical outcome. Cell Stem Cell. 2007;1(5):555-67.

120. Hermann PC, Huber SL, Herrler T, Aicher A, Ellwart JW, Guba M, et al. Distinct populations of cancer stem cells determine tumor growth and metastatic activity in human pancreatic cancer. Cell Stem Cell. 2007;1(3): 313-23.

121. Takaya A, Hirohashi Y, Murai A, Morita R, Saijo H, Yamamoto E, et al. Establishment and analysis of Cancer stem-like and non-Cancer stem-like clone cells from the human Colon Cancer cell line SW480. PLoS One. 2016; 11(7):e0158903.

122. Francescangeli F, Contavalli P, De Angelis ML, Baiocchi M, Gambara G, Pagliuca A, et al. Dynamic regulation of the cancer stem cell compartment by Cripto-1 in colorectal cancer. Cell Death Differ. 2015;22(10):1700-13.

123. Blanpain C, Simons BD. Unravelling stem cell dynamics by lineage tracing. Nat Rev Mol Cell Biol. 2013;14(8):489-502.

124. Lamprecht S, Schmidt EM, Blaj C, Hermeking H, Jung A, Kirchner T, et al. Multicolor lineage tracing reveals clonal architecture and dynamics in colon cancer. Nat Commun. 2017:8(1):1406.

125. Nguyen LV, Cox CL, Eirew P, Knapp DJ, Pellacani D, Kannan N, et al. DNA barcoding reveals diverse growth kinetics of human breast tumour subclones in serially passaged xenografts. Nat Commun 2014;5:5871.

126. Kreso A, O'Brien CA, van Galen P, Gan Ol, Notta F, Brown AM, et al. Variable clonal repopulation dynamics influence chemotherapy response in colorectal cancer. Science. 2013;339(6119):543-548.

127. Dieter SM, Ball CR, Hoffmann CM, Nowrouzi A, Herbst F, Zavidij O, et al. Distinct types of tumor-initiating cells form human colon cancer tumors and metastases. Cell Stem Cell. 2011;9(4):357-65.

128. Siegmund KD, Marjoram P, Woo YJ, Tavare S, Shibata D. Inferring clonal expansion and cancer stem cell dynamics from DNA methylation patterns in colorectal cancers. Proc Natl Acad Sci U S A. 2009;106(12):4828-33.

129. Sottoriva A, Spiteri I, Shibata D, Curtis C, Tavare S. Single-molecule genomic data delineate patient-specific tumor profiles and cancer stem cell organization. Cancer Res. 2013;73(1):41-9.

130. Pisco AO, Huang S. Non-genetic cancer cell plasticity and therapy-induced stemness in tumour relapse: 'What does not kill me strengthens me'. Br J Cancer. 2015;112(11):1725-32.

131. Colak S, Zimberlin CD, Fessler E, Hogdal L, Prasetyanti PR, Grandela CM, et al. Decreased mitochondrial priming determines chemoresistance of colon cancer stem cells. Cell Death Differ. 2014;21(7):1170-7.

132. Dylla SJ, Beviglia L, Park IK, Chartier C, Raval J, Ngan L, et al. Colorectal cancer stem cells are enriched in xenogeneic tumors following chemotherapy. PLoS One. 2008;3(6):e2428.

133. Lombardo $Y$, Scopelliti A, Cammareri P, Todaro M, lovino F, Ricci-Vitiani L, et al. Bone morphogenetic protein 4 induces differentiation of colorectal cancer stem cells and increases their response to chemotherapy in mice. Gastroenterology. 2011;140(1):297-309.

134. Todaro M, Alea MP, Di Stefano AB, Cammareri $P$, Vermeulen L, lovino F, et al. Colon cancer stem cells dictate tumor growth and resist cell death by production of interleukin-4. Cell Stem Cell. 2007;1(4):389-402.

135. Takebe N, Miele L, Harris PJ, Jeong W, Bando H, Kahn M, et al. Targeting notch, hedgehog, and Wnt pathways in cancer stem cells: clinical update. Nat Rev Clin Oncol. 2015;12(8):445-64.

136. Gong X, Azhdarinia A, Ghosh SC, Xiong W, An Z, Liu Q, et al. LGR5-targeted antibody-drug conjugate eradicates gastrointestinal tumors and prevents recurrence. Mol Cancer Ther. 2016;15(7):1580-90

137. Junttila MR, Mao W, Wang X, Wang BE, Pham T, Flygare J, et al. Targeting LGR5+ cells with an antibody-drug conjugate for the treatment of colon cancer. Sci Transl Med. 2015;7(314):314ra186.

138. Storm EE, Durinck S, de Sousa e Melo F, Tremayne J, Kljavin N, tan C, et al. targeting PTPRK-RSPO3 colon tumours promotes differentiation and loss of stem-cell function. Nature. 2016;529(7584):97-100.
139. Koo BK, van Es JH, van den Born M, Clevers H. Porcupine inhibitor suppresses paracrine Wnt-driven growth of Rnf43;Znrf3-mutant neoplasia. Proc Natl Acad Sci U S A. 2015;112(24):7548-50.

140. Batlle E, Clevers H. Cancer stem cells revisited. Nat Med. 2017;23(10):1124-34.

141. Bendell JC, Hochster H, Hart LL, Firdaus I, Mace JR, McFarlane JJ, et al. A phase II randomized trial (GO27827) of first-line FOLFOX plus bevacizumab with or without the MET inhibitor Onartuzumab in patients with metastatic colorectal Cancer. Oncologist. 2017;22(3):264-271.

142. van der Horst EH, Chinn L, Wang M, Velilla T, Tran H, Madrona Y, et al. Discovery of fully human anti-MET monoclonal antibodies with antitumor activity against colon cancer tumor models in vivo. Neoplasia. 2009;11(4): 355-364.

143. Gupta PB, Fillmore CM, Jiang G, Shapira SD, Tao K, Kuperwasser C, et al. Stochastic state transitions give rise to phenotypic equilibrium in populations of cancer cells. Cell. 2011;146(4):633-44.

144. Zeuner A, Todaro M, Stassi G, De Maria R. Colorectal cancer stem cells: from the crypt to the clinic. Cell Stem Cell. 2014;15(6):692-705.
Ready to submit your research? Choose BMC and benefit from:

- fast, convenient online submission

- thorough peer review by experienced researchers in your field

- rapid publication on acceptance

- support for research data, including large and complex data types

- gold Open Access which fosters wider collaboration and increased citations

- maximum visibility for your research: over $100 \mathrm{M}$ website views per year

At BMC, research is always in progress.

Learn more biomedcentral.com/submissions 